\title{
A Study on the Relationship between Vocational Education Development and Enterprise Technical Innovation
}

\author{
Qi Xuan \\ Institute of Education Economics and Administration \\ University of Science and Technology Beijing \\ Beijing,China \\ 15810801000@139.com
}

\begin{abstract}
Vocational education, as the talent base for an enterprise to develop, is endowed with the mission of cultivating skill-type talents. Therefore, the quality of vocational education development would determine the quality of skill-type talent cultivation and the quality of talents would affect an enterprise's technical innovation potential to some extent.
\end{abstract}

Keywords-Vocational Education; Enterprise; Technical Innovation

An enterprise's innovation ability serves as its lifeblood. During the transformation and upgrading process of an enterprise from simple reliance on labor quantity to quality in development, vocational education development has laid a firm foundation for the development of an enterprise. Vocational education, via fostering talents with both professional speculative knowledge and professional skills, establishes a talent foundation and a technical foundation for the innovation and development of an enterprise. "university-enterprise cooperation”, "oriented cultivation”, "talent order" and many other famous terms occur successively, which has fully explained the significance of vocational education in the technical innovation of an enterprise.

\section{INTRODUCTION TO THE FUNCTIONS OF VOCATIONAL} EDUCATION ON AN ENTERPRISE’S DEVELOPMENT

\section{A. skill-type talent}

Key factors in deciding an enterprise's development include not only equipment's content of science and technology, but also skill-type talent. Because they work at the forefront of production, proficiency in grasping and applying the techniques, skills would directly affect the production and development of an enterprise.

\section{B.vocational education and skill-type talent}

However, vocational education, as a professional base for cultivation of technical and skill-type talents, is mainly for doing a good job in incubation and reservation of talents for the development of an enterprise. Its role is mainly embodied in three aspects: first, the theoretical preparation for an enterprise's technical innovation. Because of the professionalism in teaching and education knowledge, vocational education carries out systematical integration of relevant theoretical knowledge to prepare for the innovation of technical theory; second, talent preparation for an enterprise's technical innovation. Because the vocational education is for directly cultivating oriented skill-type talents for an enterprise, including some students fond of learning, studying and students with specialties, who, once take a post in an enterprise, will grow for the technical innovation combining their expertise, professional knowledge and job needs; third, preparation of front-line workers for the development of an enterprise. This is the most basic function of vocational education, no matter what kind of innovation. Only based on the solid work done by front-line workers can an enterprise shine.

\section{ANALYSIS ON AN ENTERPRISE’S TECHNICAL INNOVATION CONDITIONS}

\section{A. necessary conditions for innovation}

For an enterprise to achieve technical innovation, the following necessary conditions must be obtained: a number of technical personnel, talent cultivation base and environmental protection for encouraging technical innovation.

\section{B.the cooperation with occupation education schools}

Then, where do technical talents come from? This requires deepening the cooperation with occupation education schools. To meet the recruitment needs, we can also have order training for technical workers without systematic learning. Based on systematic education being received and technology being mastered skillfully, innovation can be realized. Talent cultivation base is for "excellence from quantity", "optimal from excellent". As the filter used by an enterprise, this process can ensure the automatic updates and upgrades of the level of talent, so as to ensure an enterprise's innovation ability enhancement.

\section{C. enterprises environment for innovation}

At the same time, enterprises should create a relaxed, incentive environment, providing guarantee from systems to fully protect and utilize the enthusiasm of enterprises' staff innovation.

\section{RESEARCH ON THE RELATIONSHIP BETWEEN} VOCATIONAL EDUCATION DEVELOPMENT AND ENTERPRISE TECHNICAL INNOVATION

Vocational education, as an incubation process for a person from a student to a skilled worker, is for directly 
fostering skill-type talents for an enterprise. Talents are just like the bridge between vocational education development and an enterprise's technical innovation. Higher talent level leads to stronger innovation ability.

\section{A. Talents Cultivation}

An enterprise develops depending on talents. Front-line positions, particularly, require skill-type talents with professional knowledge. The significance of talent cultivation lies in utilizing professional knowledge in production. What en enterprise needs are talents who could go into service and play functions at a lower cost on training. Vocational education, via specific education and teaching methods, especially accumulation in practical training stage, causes students after graduation ready to take office upon graduation.

Talents cultivated via vocational education are able to carry out simple maintenance on equipment. Since most of the students with vocational education have learned something about equipment manufacturing, structuring and principle more or less, in case of small failures on equipment, they could implement basic treatment and maintenance to avoid any influence on normal work and prevent the problem for expanding.

Such talents could also do some simple or even great innovation on the professional bases. Some vocationally educated students focus on the development of hobbies or specialty, and surely they will make significant contributions on their posts.

\section{B. Theoretical Innovation}

Graduates from vocational school have experienced at least 3-years systematic school education with relatively comprehensive and systematic grasping of various kinds of theoretical knowledge, which establish a foundation for their theoretical innovation further.

First, theoretical innovation on process. To most of the graduates from vocational education, they are engaged in technical work at the frontline upon their graduation. Therefore, they have a better and more precise understanding on their equipment, and the overall comprehension of advantages and shortcoming of such equipment will be deepened along with their working experience increasing. Particularly, their understanding on shortcomings will provide conditions for their theoretical innovation on equipment process.

Second, technical theoretical innovation. For those expert and gifted graduates from vocational schools, they would find the technical faults of a set of equipment, the entire production line or even the whole enterprise, and they are able to make some technical theoretic innovation practically. Such innovation will greatly improve an enterprise's innovation ability, supporting the enterprise's leading position in the same industry.

Third, skill theoretical innovation. Skill refers actual operation ability. Though everyone can do simple operation, great differences still exist among people of different skill levels. People with skills and innovation methods could not only improve production efficiency, but also make a contribution to technical innovation which is also an important embodiment of an enterprise's innovation ability.

\section{Innovative Enlightenment}

Vocational education's function on an enterprise's enlightenment on technical innovation shall never be omitted. It can also be called as "the cultivation function on inspiration". Such innovative inspiration mainly shows in following several aspects.

First, innovative enlightenment on positions. When a student graduates from an vocational school and enters into an enterprise, he would actively develop his enthusiasm in his work, applying all knowledge he has learned into his position. No matter it is for personal comfort in work and living, or for serving the enterprise's development, he could make proper adjustment according to his position. During the process, position features would be adjusted according to personal conditions.

Next, enlightenment on improvement and upgrade of equipment in production line. Incented by business consideration, all workers will work hardly and try to activate their innovation potential. They will try all means, such as improvement of equipment process, to realize the production state of high efficiency and lower faults, so as to achieve their higher pursuits on higher quantity of work in unit time. Both processes are actually for innovation, during which, innovation concepts can be generated and then innovation methods are formed.

\section{CONCLUSION}

All in all, the virtuous development of vocational education is for a foundation of talents for innovative development of an enterprise. Meanwhile, via accumulation of various innovation abilities on professional technical innovation theories, professional technical innovation inspiration and professional technicians, technical innovation, skill innovation and equipment process innovation are achieved step by step.

\section{REFERENCES}

[1] Guan Ping. Enterprise Technical Innovation and Innovative Hi-tech Talents Cultivation [J].Heilongjiang Higher Education Research Institute, 2011 (7)

[2] Wang Jiaofan. Research on the Industry-University-Research Cooperation Talent Cultivation Mode in Higher Vocational Education [J]. Heilongjiang Institute of Science and Technology, 2011.

[3] Su Xifeng. Problems in Higher Vocational Innovative Education and Countermeasures [J]. .Heilongjiang Higher Education Research Institute, 2004 (9).

[4] Du Haoming, Wang Jun. Scientific and Technical Innovation Education from Skill-type Students from Higher Vocational Education [J]. Jiangxi Education, 2010 (30).

[5] Curtis Finch,John Crunkilton.Curriculum Development in Vocational and Technical Education[M].Aviacom Company,2001.

[6] UNESCO.World Date on Education[M].International Bureau of Education,2004. 